\title{
FENFLURAMINE CHALLENGE TEST IN OBSESSIVE-COMPULSIVE DISORDER - FIRST RESULTS
}

\author{
Vladimír Pidrman, Ivan Tůma \\ Department of Psychiatry, Charles University, Faculty of Medicine, Hradec Králové; \\ (Head: doc. MUDr. H. Hanuš, CSc.)
}

\begin{abstract}
Summary: Obsessive-compulsive disorder is a chronic psychiatric illness, affecting up to $3 \%$ of the general population, to the midle of 60-th it was supposed to be untreatable. Antidepressant pharmacotherapy is one of the treatment alternatives today. We compared efficacy and safety of citalopram versus clomipramine (serotoninergic antidepressants) in 6 weeks in double blind therapy of obsessive-compulsive disorder. The second objective was to compare prolactin response to a fenfluramine challenge test before the treatment of patients and after 6 weeks of the treatment. In a sample of 14 patients we confirmed significant therapeutic response after 3 weeks of pharmacoterapy, better in obsession than in compulsion. We found low level of adverse effects in the first week of therapy - dry mouth, anxiety, nausea, somnolence, tremor, and sexual adverse events. There were no changes in the laboratory, test EEG, and ECG examinations. Fenfluramine challenge test showed statistically significant decrease of prolactine levels 1 hour after administration of fenfluramine. It was not observed after six weeks of the therapy. Statistically significant negative correlation between prolactine plasma levels at the 6-th hour after administration of fenfluramine and obsession item of YBOC Scale was showed after the 3-rd and 6-th week of the therapy. The correlation was not observed for compulsion item YBOC Scale. Side effects observed during and after the challenge test were anxiety and nervousness and gastrointestinal problems, lasted from 1 hour to 10 hours. These preliminary result could support the idea, that obsessions and compulsions have not necessary the same biological background. The challenge paradigm appears to be a possible way to clarify the pathogenesis of OCD. Our study will continue.
\end{abstract}

Key words: Obsessive-compulsive disorder; Fenfluramine

\section{Introduction}

Obsessive-compulsive disorder (OCD) is a common, chronic psychiatric illness, affecting up to $3 \%$ of the general population. In spite of the high relatively prevalence, relatively few patients seek the treatment.

There are two alternatives of the therapy. The first one is a psychotherapy, especially cognitive behavioral therapy, the second one is pharmacoterapy. From 1967 is known that antidepressant drug clomipramine may be more succesful than other agents (2).

Recent evidence has led to the hypothesis that abnormalities in serotonin metabolism play a significant role in the pathogenesis of OCD. Clomipramine was the first antidepressant with serotoninergic activity higher than other antidepressants in 60-th and 70-th (16). Today new potent antidepressants - serotonin selective reuptake inhibitors (S.S.R.I.) have demonstrated antiobsessional and anticompulsional efficacy similar to clomipramine in a number of studies $(3,9,17,21)$.

The results of studies employing neuroendocrine challenge tests sugest that serotonin receptors may be altered in
OCD too $(5,6)$. The serotonin hypothesis receives support from a paper by Lucey et al. (12), who compared the prolactin response to d-fenfluramine, a serotonin releasing agent. The blunted prolactin response after d-fenfluramine was seen in the patients group.

Fenfluramine (dextro isomer of n-ethyl-alfa- methyl- 3fluoromethyl-phenethylamine) is a indirect serotonin (5-HT) agonist in the brain, a stimulator of the release of prolactin from the anterior pituitary gland through a serotonin mechanism and an indicator of the ability of the activation of the central serotonin system.

Fenfluramine test is studied as a marker of obsessivecompulsive symptoms and a predictor of a therapeutic response to a pharmacotherapy in OCD (1).

In the double-blind study we compare citalopram (potent S.S.R.I) versus clomipramine (first and classical drug in this field) in the therapy of obsessive-compulsive disorder with the aim to evaluate their efficacy and safety. The objective is to compare prolactin response to a fenfluramine challenge test before treatment of OCD patients by serotoninergic drugs, after 6 weeks of treatment and in a small group after 6 months of follow up. 


\section{Material and methods}

The study group consisted of 14 patients ( 9 male, 5 female, mean age 33,7 years, ranging from 22 to 52 years). The patients, who were at least 18 years old and met the ICD-1O criteria for OCD for 6 months or longer and scored minimum 18 at YBOC Scale, were considered for participation. Women who were pregnant, lactating, or not using reliable contraception were not be enrolled. Other exclusion criteria included significant concomitant physical disease, depression with 17 item HAMD total score more than 22, suicidal tendency, a history if seizure or organic brain disorder, substance abuse.

Patients who met inclusion criteria signed Informed Consent. Physical examination and medical work up (including ECG and blood laboratory tests) were provided. After one week of wash-out period the double-blind study was started. Psychiatric examination included YBOCS (Yale-Brown Obsessive-Compulsive Scale) (4), HAMD (17 item Hamilton Depression Scale) (7) and CGI (Clinical Global Impression). EEG examination was made in the first day of double-blind medication, before the first dose of the active drug. The next one was made after 21 days and the last one after 42 days. Side effect occurrence was observed daily in the first week, than in the rating days. Five patients continued study till the 6-th month, when these examinations were made again.

\section{Fenfluramine challenge test and blood samples}

The first fenfluramin test has been carried out day before the treatment was started. The patients were in fasting and nonsmoking state over the night, $60 \mathrm{mg}$ of d-fenfluramine (Isolipan caps.) was given per os at 6 A.M. immediatelly, after the first blood sample.

The second test has been done after 42 days therapy. In five patients after 6 months too.

Blood samples for the assessment of prolactin levels were taken at $6,7,8,10,12$ A.M. from a peripheral vein.

The patients were asked about feelings and adverse effects during and after the test.

The levels of prolactine have been assessed by immunoluminescence method (5).

\section{Medication}

Identical capsules containing either citalopram $20 \mathrm{mg}$ or clomipramine $75 \mathrm{mg}$. Under double-blind condition one capsule has been served once daily at 12 A.M. According to the result of examination in day 21 it could (no change or worsening in YBOCS) be increased to two capsules a day (at 8 and 12 A.M.). The medicacion was started the first day after fenfluramine challenge test.

\section{Results}

14 patients were randomized to double-blind treatment with citalopram $(\mathrm{N}=7)$ or clomipramine $(\mathrm{N}=7)$. The code was not opened yet.
YBOCS evaluation showed significant improvement (scale score decrease) from baseline in the end of the third week of therapy. This decrease was greater in the end of the sixth week and a trend continued till the sixth month. Obsession item improvement is faster in the beginning, than compulsion one. See fig.1, 2, 3 .

Fig. 1: Yale-Brown Obsessive Compulsive Scale (Y-BOCS); average total sample score $(\mathrm{N}=14 /$ day 0 - 6 th week/; $\mathrm{N}=5 / 6$-th month/)

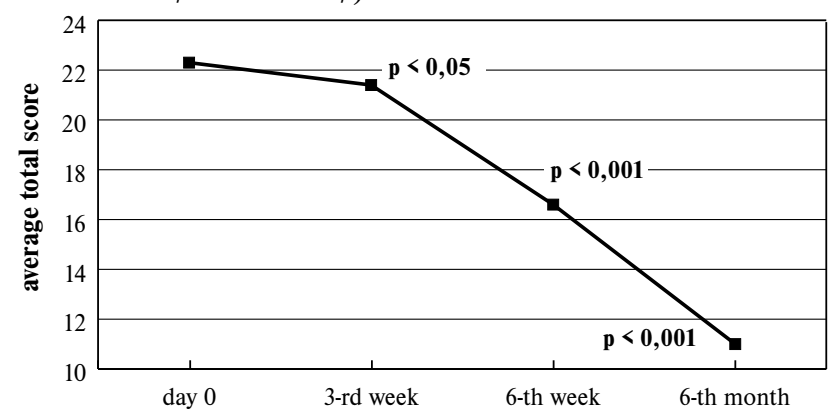

Fig. 2: Yale-Brown Obsessive Compulsive Scale (Y-BOCS); average obsession item score $(\mathrm{N}=14$ /day 0 - 6 th week/; $\mathrm{N}=5 / 6$-th month/)

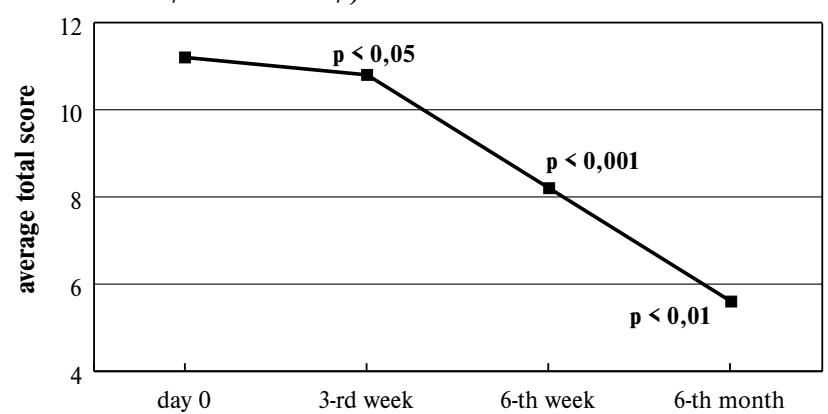

Fig. 3: Yale-Brown Obsessive Compulsive Scale (Y-BOCS); average compulsion item score $(\mathrm{N}=14 /$ day 0 - 6 th week/; N=5/6-th month/)

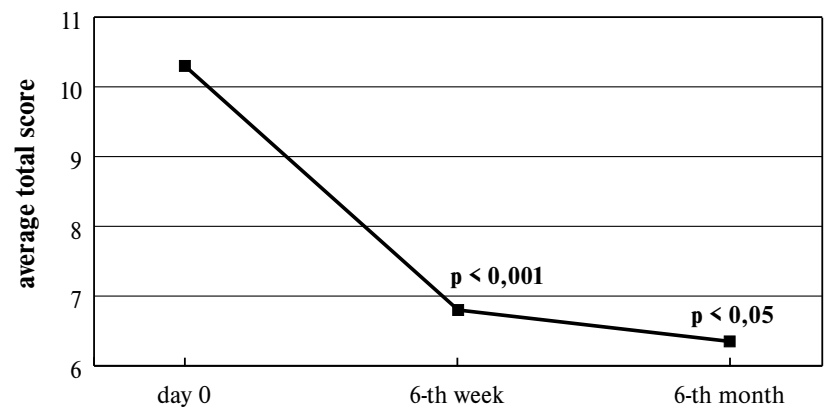

HAMD evaluation indicated statistically significant improvement in the end of sixth week, trend continued till month 6. See fig. 4 .

CGI scale showed significant improvement begining the end of the sixth week, in the case of 5 patients in follow up till month 6 , see fig. 5 . 
Fig. 4: Hamilton depressive scale; average total sample score $(\mathrm{N}=14 /$ day 0 - 6 th week/; $\mathrm{N}=5 / 6$-th month/)

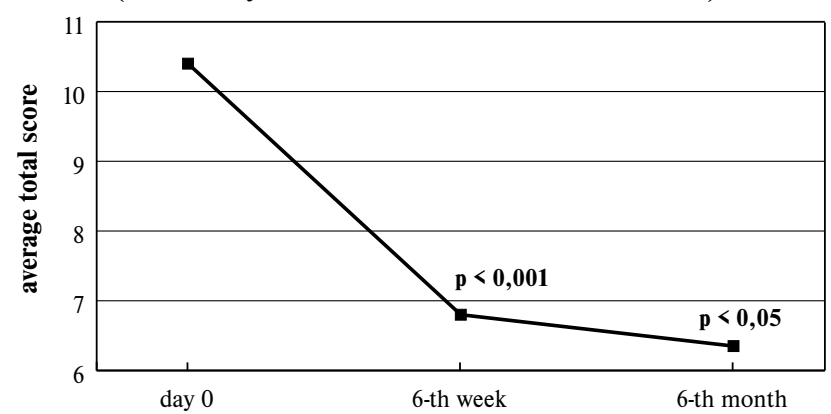

Fig. 5: Clinical global impression; average total sample score $(\mathrm{N}=14 /$ day 0 - 6 th week/; $\mathrm{N}=5 / 6$-th month/)

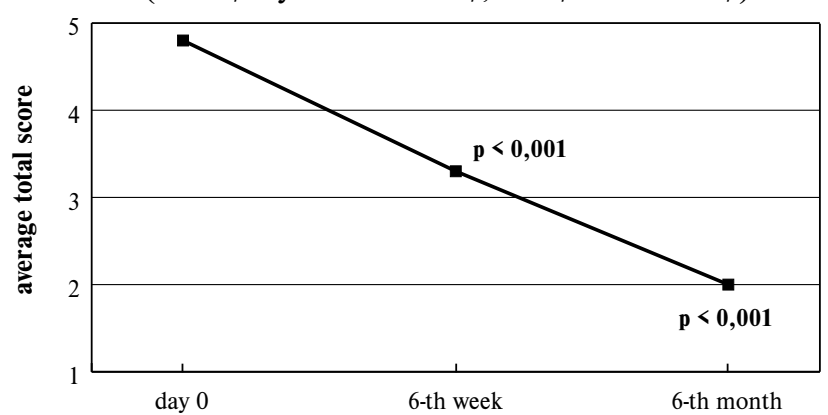

Side effects in the first therapy week were dry mouth $(\mathrm{N}=2)$, anxiety $(\mathrm{N}=2)$, nausea $(\mathrm{N}=2)$, somnolence $(\mathrm{N}=2)$, tremor and sexual adverse events in 1 case. After three weeks of therapy they were: dry mouth, anxiety, somnolence, tremor and sexual adverse events in one subject. In the sixth week dry mouth, tremor and sexual side effects lasted in 1 case.

Laboratory blood, EEG and ECG examination were not changed in the six weeks of study, neither in a group of five patients after 6 month of therapy.

Fenfluramine challenge test showed statistically significant decrease of prolactine levels in the 1-st hour after admission of d-fenfluramine. It was not seen ater six weeks of therapy (T-test), see fig. 6 .

Fig. 6: Fenfluramine test; prolactine (PRL) levels before and after $60 \mathrm{mg}$ d-fenfluramine admission

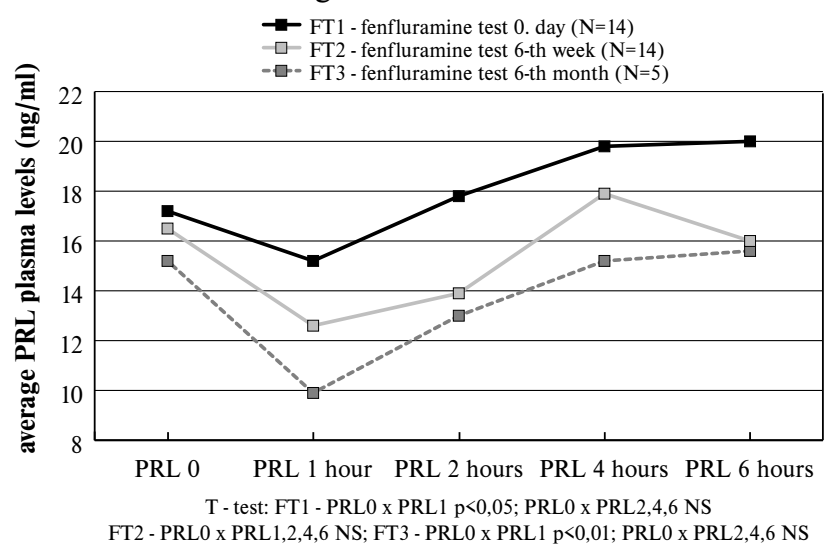

Statistically significant negative correlation between prolactine plasma levels in the 6-th hour after the admission of d-fenfluramine and obsession item of YBOC Scale was showed after the 3-rd and 6-th week of therapy (multiple rergession analysis) as well.

Side effects during and after the test were observed: anxiety and nervousness in 2 cases, gastrointestinal problems in 1 case. They continued from 1 hour to 10 hours.

\section{Discussion}

Fenfluramine is a serotonin (5-HT) agonist agent. Because fenfluramine enhances the release of 5-HT and also inhibit re-uptake of 5-HT it stimulants both pre- and postsynaptic receptors. Challenge studies with fenfluramine in OCD are rare, but some available evidence indicates, that it could be a "window" to the functional status of 5-HT system in OCD (20). A blunted plasma prolactin response to fenfluramine challenge (more in female) was reported in patients group by Hewlett and Martin (8). Lucey and coworkers $(12,14)$ found blunted prolactin response to fenfluramine challenge in patients group. Controversial results were reported by Hollander (9) and Price (19). They found identical prolactin response to fenfluramine in OCD patients and controls.

The abnormal prolactin response is not confirmed to OCD. Similar blunted responses to fenfluramine challenge have been reported in depressed patients $(12,15)$. Considering the fact that the prolactin response to fenfluramine is mediated through 5-HT receptors - subtype $2 \mathrm{~A}$ and $2 \mathrm{C}$, it is conceivable that these receptor subtypes are involved in the pathogenesis of OCD (13). The notion of altered sensitivity is, not easily explained in therm of a super- or subsensitivity. A behavioral response to m-chlorophenylpiperazine, a $5-\mathrm{HT}_{2 \mathrm{~A} / 2 \mathrm{C}}$ agonist could be indicative of supersensitivity of those receptors $(6,18)$. On the other hand in studies in which a blunted prolactin response to challenge with fenfluramine was found, these findings could be interpreted as an evidence for subsensitivity of the same subtype of receptors $(10,11)$. A reason for the lack of consistency in the behavioural and neuroendocrine results of challenge studies in OCD may be that the dysfunction possibly is confined to a specific subgroup of OCD patients, we could not diverse in exploration, whereas clinical studies have been on all OCD patients population $(9,14,22)$. Other reasons for that fact could be the multiple influences to challenge test, for example sex, age, level of anxiety and/or stress (21).

Our results are preliminary, in a small sample of patients, it is reference from the first year of study. We consider interesting result of negative correlation of prolactine plasma levels and obsession item of YBOCS. Respecting small number of patients it could support the idea, that obsessions and compulsions have not necessary the same biological background. We can not answer the question of predictive value of fenfluramine challenge tests yet. The larger sample of patients is necessary. 
Our results demonstrate that citalopram is as effective as clomipramine in the treatment of patients with OCD. We confirm safety of both drugs, there were low level of side effect and no laboratory, EEG or ECG changes. Results of fenfluramine challenge test do not show predicting value in a sample of 14 patients. The group of 5 patients followed for 6 months is too small to make any conclusions.

The challenge paradigm appears a way to clarify at least the part of the pathogenesis of OCD, although not many consistent findings have been reported yet. The papers described above do support the 5-HT theory of OCD.

\section{References}

1. Charney DS, Goodman WK, Price LH, Woods SW, Rasmussen SA, Heninger GR. Serotonin function in obsessive-compulsive disorder. Arch Gen Psychiatry 1988;45:177-85

2. Fernandez-Cordoba E, Lopez-Ibor AJ. La monoclomipramina en enfermost psiquiatricos resistentes a otros tratamientos. Acta Luso-Esp Neurol Psiq Ciene Afines 1967;26:119-47.

3. Goodman WK, Price LH, Delgado PL et al. Specificity of serotonin reuptake inhibitors in the treatment of obsessive-compulsive disorder. Arch Gen Psychiatry 1990;47:577-85.

4. Goodman WK, Price LH, Rasmussen SA et al. YaleBrown Obsessive-Compulsive Scale. Arch Gen Psychiatry 1989;46:1006-16.

5. Goodman WK, Price LH, Woods SW, Charney DS. Pharmacologic challenges in obsessive compulsive disorder. In: Zohar J, Insel T, Rasmussen S, (Eds.). The Psychobiology of Obsessive-compulsive disorder. New York: Springer Verlag 1991;162-86.

6. Goodman WK, McDougle C, Price LH et al. $\mathrm{m}$ Chlorophenylpiperazine in patiens with obsessive compulsive disorder: absence of symptom exacerbation. Biol Psychiatry 1995;38:138-49.

7. Hamilton M. A rating scale for depression. Neurol Neurosurg Psychiat 1960;23:562.

8. Hewlett WA, Martin K. Fenfluramine challenges and serotonergic functioning in obsessive compulsive disorder. Presented at First International Obsessive-compulsive disorder Congress, Capri, Italy, 1993, 12-13 Mar.

9. Hollander E, DeCaria CM, Nitescu A et al. Serotonergic function in obsessive-compulsive disorder. Arch Gen Psychiatry 1992;49:21-8.

10. Hollander E, Fay M, Cohen B, Campeas R, Gorman JM, Liebovitz MR. Serotonergic and adrenergic sensitivity in obsessive-compulsive disorder: Behavioral findings. Am J Psychiatry 1988;145:1015-17.
11. Insel TR, Donnelly EF, Lalakea ML et al. Neurological and neuropsychological studies of patients with obsessivecompulsive disorder. Biol Psychiatry 1983;18:741-51.

12. Lucey JV, O Keane V, Butcher G, Dinan GT. Cortisol and prolactin responses to d-fenfluramine in normotensive obsessive disorder, a comparison with depressed and healthy controls. Br J Psychiatry 1992;161:517-21.

13. Lucey JV, Butcher G, Clare AW, Dinan TG. Buspironeinduced prolactin responses in obsessive compulsive disorder. Int J Psychopharmacology 1992;7:45-9.

14. Lucey JV, Butcher G, Clare AW, Dinan TG. The anterior pituitary responds to prolactin in obsessive compulsive disorder : evidence to support a neuroendocrine serotonergic deficit. Acta Psychiatr Scand 1993;87:384-8.

15. McBride PA, DeMeo MD, Sweeney JA, Halper J, Mann JJ, Shear MK. Neuroendocrine and behavioral responses to challenge with the indirect serotonin agonist d-fenfluramine in adults with obsessive compulsive disorder. Biol Psychiatry 1992;164:19-34.

16. Montgomery SA. Clomipramine in obsessional neurosis: a placebo-controlled trial. Pharm Med 1980;1:189-92.

17. Montgomery SA, McIntyre A, Sterheider $M$ et al. A double-blind, placebo-controlled study of fluoxetine in patients with DSM-III-R obsessive compulsive disorder. Eur Neuropsychopharmacology 1993;3:143-52.

18. Pigott TA, Yoney TH, L Heureux F. Serotonergic responsivity to $\mathrm{m}$-CPP in OCD patients during clomipramine and fluoxetine treatment. Biol Psychiatry 1990;27:14A-17A. 19. Price LH, Charney DS, Delgado PL, Anderson GM, Heninger GR. Effects of desipramine and fluvoxamine treatment on the prolactin response: Serotonin function and the mechanism of antidepressant action. Arch Gen Psychiatry 1989;46:625-31.

20. Swinson RP, Joffe RT. Biological challenges in obsessive compulsive disorder. Prog Neuropsychopharmacol Biol Psychiatry 1988;12:269-75.

21. Tollefson GD, Rampey AH, Potvin JH et al. A multicenter investigation of fixed-dose fluoxetine in the treatment of obsessive compulsive disorder. Arch Gen Psychiatry 1994;51:559-67.

22. Zohar J, Mueller EA, Insel TR. Serotonin responsivity in obsessive compulsive disorder. Arch Gen Psychiatry 1987;44:946-51.

Submitted October 1997.

Accepted November 1997.

\author{
MUDr. Vladimír Pidrman, \\ Department of Psychiatry, \\ Charles University, Faculty of Medicine, \\ 50005 Hradec Králové, Czech Republic.
}

